\title{
Development of a Purified Viral Preparation for Studies of COVID-19 (SARS-CoV-2) Biology
}

\author{
A. A. Chepurnov, E. I. Kazachinskaya, E. A. Kazachkova, \\ K. A. Sharshov, Yu. V. Kononova, A. A. Shelemba, A. Yu. Alekseev, \\ M. A. Gulyeva, M. I. Voevoda, and A. M. Shestopalov
}

Translated from Byulleten' Eksperimental'noi Biologii i Meditsiny, Vol. 172, No. 7, pp. 60-64, July, 2021

Original article submitted June 4, 2021

Different methods for producing bulk quantities of concentrated and purified SARS-CoV-2 for the use as antigens and for the research into COVID-19 biology were tested.

Key Words: SARS-CoV-2; 2002 year SARS-CoV; electrophoresis; purified virus preparations

The pandemic of 2019 (COVID-19), caused by the SARS-CoV-2 coronavirus, is a global threat to the human health [14]. The vaccines for COVID-19 prevention and control as well as the tools for detection of antibodies and studies of the specific features in immunopathogenesis and the mechanisms underlying other pathologies are urgently developed. The current level of biotechnology allows these problems to be solved by producing recombinant SARS-CoV-2 proteins (or constructed by some other ways). However, production of the sufficient quantities of purified concentrated whole-virion SARS-CoV-2 preparation also makes it possible to effectively solve these and other related problems using the native material $[7,8,11]$. Chinese researchers, who were the first to encounter SARS-CoV-2, also attempted to use purified whole-virion virus preparations for both research purposes and development of inactivated vaccine $[9,13]$.

Having isolated a SARS-CoV-2 strain [4], we attempted to obtain a purified whole-virion SARS-CoV-2 preparation, because the key point was to enable the serological studies and provide the material for the trials of comparative

Federal Research Center of Fundamental and Translational Medicine, Novosibirsk, Russia. Address for correspondence: alexa.che.purnov@, gmail.com. A. A. Chepurnov effectiveness of injection and intranasal vaccination with the inactivated vaccine prototype.

In this paper, we describe the method that we used for production, concentration, and purification of a whole-virion SARS-CoV-2 preparation.

\section{MATERIALS AND METHODS}

Virus SARS-CoV-2. The virus was isolated from patients with positive PCR test for COVID-19 from the nasopharyngeal lavage samples that demonstrated a cytopathic effect (CPE) on African green monkey kidney cell (Vero) monolayer. In order to detect the most productive isolates, the recovered ones were used to infect the Vero cell monolayer and the harvested virus was used to infect an intact Vero cell monolayer. A series of the successive blind procedures led to selection of the most productive of the recovered isolates. The resulting strain was produced by infecting the Vero cell culture at an infective dose of $0.01 \mathrm{CPE} /$ cell. On day 5 , the vial with total CPE and $100 \%$ cell separation from plastic was subjected to triple freezing/thawing; the contents were transferred to a centrifuge tube, clarified by centrifugation at $6000 \mathrm{rpm}$ for $10 \mathrm{~min}$, packed for a long-term storage, and placed into a low-temperature freezer. 
The titer of the virus determined by endpoint dilution technique was $5 \times 10^{6} \mathrm{CPE} / \mathrm{ml}$. The resulting isolate was characterized and its genetic homogeneity was confirmed. The virus is deposited with the collection of viruses of the $48^{\text {th }}$ Central Research Institute of the Ministry of Defense of the Russian Federation, under the name SARS-CoV-2/human/RUS/NskFRCFTM-1/2020 [4].

Cell cultures. We used continuous Vero and embryonic porcine kidney epithelial cell line (SPEV) obtained from the N. F. Gamaleya National medical Research Center of Epidemiology and Microbiology. The cells were cultured in MEM supplemented with $10 \%$ fetal bovine serum and $1 \%$ antibiotic/antimycotic (Gibco). Then, productivity of the obtained SARSCoV-2 strain was studied in different cell cultures. In each case, 3 passages on the studied cell culture were preliminary performed.

Evaluation of virus titer. Virus titers were determined by endpoint dilution technique. To this end, the corresponding wells of 96 -well plates containing a cell culture was infected with 10 -fold virus dilutions in Hank's solution. The titration by a plaque technique in cell culture monolayer under a semiliquid agar, analogous to that described for Ebola virus [1], was also used. Briefly, a semiliquid 0.06\% agar (Difco) was prepared using bidistilled water and sterilized by autoclaving at $1 \mathrm{~atm}$ for $45 \mathrm{~min}$. The Eagle's MEM $(\times 2)$ containing $44.8 \mathrm{ml}$ medium, $2 \mathrm{ml}$ fetal bovine serum, $3 \mathrm{ml} 7.5 \%$ sodium bicarbonate, and $100 \mu \mathrm{g} / \mathrm{ml}$ kanamycin, was mixed with agar at a ratio of $1: 1$. The plaques were counted after staining the cell monolayer with gentian violet $(0.1 \mathrm{~g}$ dye was dissolved in $10 \mathrm{ml}$ ethanol and the volume was brought to $100 \mathrm{ml}$ with distilled water).

Virus concentration and purification. SARSCoV-2 was concentrated and purified by ultracentrifugation in an L8 Beckman centrifuge (rotors Type $45 \mathrm{Ti}$ and SW 28). After recording a $100 \%$ $\mathrm{CPE}$, the entire content of the culture vials infected as described above was transferred into the centrifuge tubes for a Type 45 Ti rotor (Beckman). This allowed us to simultaneously centrifuge $(40,000 \mathrm{rpm}$, $80 \mathrm{~min}) 420 \mathrm{ml}$ of the virus-containing culture fluid (VCF). The pellet was suspended in PBS and either homogenized in a Dounce homogenizer or three times frozen/thawed. The resulting suspension was clarified by low-speed centrifugation. The sediment was discarded and the supernatant was further purified by centrifugation in an SW 28 rotor through 15 and $30 \%$ sucrose solutions at $25,000 \mathrm{rpm}$ for $5 \mathrm{~h}$. The sedimented virus was suspended in a minimal volume and centrifuged again at $10,000 \mathrm{rpm}$ for $7 \mathrm{~min}$. The final supernatant represented a highly purified SARSCoV-2 suspension.

\section{RESULTS}

Concentrated purified whole-virion inactivated virus preparations are traditionally used for rapid development of serodiagnosis and inactivated vaccines as well as for the study of modulatory effects of both a wholevirion construct and individual virus proteins on the immunity, homeostasis, etc. [3,6]. The purified inactivated viruses are conventionally used for development of vaccines; moreover, vaccines of this type are safe and effective in preventing diseases caused by viruses. Although new modern methods of vaccine design have emerged, this type of vaccines is still the main tool for controlling influenza, tick-borne encephalitis, and many other diseases [12].

Testing for antibodies is an important component in the multipurpose approach to estimation of both the fact that a person has had a disease and the efficiency of designed vaccines [11]. Although current technologies provide a considerably simpler diagnosis relying on recombinant proteins as well as other approaches to obtaining the target proteins for mass screening, the native preparations are much more helpful in the research. We also believed that it was reasonable to design an intranasal preparation for vaccination based on an inactivated whole-virion virus delivered with the help of a lipid adjuvant, as we did earlier $[2,5,10]$.

Thus, the purified concentrated whole-virion virus preparation is a useful tool for various primary studies. Before attempting to obtain such preparation, we isolated our own production strain from patients as described above.

The resulting strain was characterized and its genetic homogeneity was confirmed. The virus is deposited in the collection of viruses of the $48^{\text {th }}$ Central Research Institute of the Ministry of Defense of the Russian Federation, under the name SARS-CoV-2/human/RUS/Nsk-FRCFTM-1/2020 [4]. The strain was produced in bulk by infecting the Vero cell culture with an infective dose of $0.01 \mathrm{CPE} /$ cell. On day 5 at a total $\mathrm{CPE}$ and $100 \%$ cell separation from plastic, the culture vial with its contents was three times frozen/thawed; the contents were transferred to a centrifuge tube for $10 \mathrm{~min}$, packaged for a long-term storage, and placed into a low-temperature freezer. The titer of the virus determined by endpoint dilution technique was $5 \times 10^{5}$ CPE $\mathrm{ml}^{-1}$.

The productivity of the obtained strain was studied using 17 cell cultures (special report will be published). The continuous Vero cell culture from our collection and SPEV culture from the collection of N.F. Gamaleya National medical Research Center of Epidemiology and Microbiology were most productive.

The procedure of virus harvesting, its concentration, and purification has different solutions. For 
example, multiple removal/addition of the medium followed by concentration using dynamic ultrafiltration and final purification by ultracentrifugation in sucrose gradient was used for obtaining the purified preparation of Ebola virus produced into culture medium [3]. During production of concentrated preparations of SARS strain Frankfurt 2002, the virus was concentrated from VCF using PEG-8000 [2].

The initial stage in the production of purified SARS-CoV-2 is determination of the optimal time moment for virus harvesting and the substrate for isolation of the virus (VCF or cells). A 2-day-old Vero cell monolayer with a $100 \%$ confluence was infected with SARS-CoV-2 in a dose of $0.01 \mathrm{CPE} /$ cell. Total $\mathrm{CPE}$ with cell rounding and $100 \%$ separation from the substrate was observed on day 5 after infection. The contents of vials were collected into centrifuge tubes to separate the cells from VCF by centrifugation for $10 \mathrm{~min}$ at $6500 \mathrm{rpm}$. Then, the virus from the VCF was sedimented by ultracentrifugation in a Type 45 Ti rotor at 40,000 rpm for $80 \mathrm{~min}$. The sediment was suspended in a comfort volume and purified in $30 / 50 \%$ sucrose density gradient.

The virus from the cells was isolated using the cell destruction by triple freezing/thawing, homogenization in a Dounce homogenizer, or addition of $0.5 \%$ detergent Igepal CA 630. The latter variant was rejected because it caused virion destruction. Ultrasound was not used. The triple freezing/thawing and homogenization with a glass Dounce homogenizer followed by low-speed centrifugation allowed us to obtain a concentrated virus suspension suitable for the virus purification in sucrose density gradient. The yields of the purified virus from VCF and the cells were approximately the same. Hence, both components can be used as a source of the virus concentration and purification. Therefore, the following approach was used for both Vero and SPEV cells. The VCF and cells at the stage of total CPE were transferred from the culture vials to the centrifuge tubes for a Type $45 \mathrm{Ti}$ rotor and centrifuged at $40,000 \mathrm{rpm}$ for $80 \mathrm{~min}$. The pellet containing both the virus and cells was suspended in PBS and homogenized in a Dounce homogenizer. The resulting suspension was clarified by low-speed centrifugation to remove the cell debris. The sediment was eliminated and the supernatant was further clarified by centrifugation through $15 / 30 \%$ sucrose gradient in an SW 28 rotor at $40,000 \mathrm{rpm}$ for $5 \mathrm{~h}$. The pellet was suspended in a minimal volume and again centrifuged at 10,000 rpm for $7 \mathrm{~min}$. The last supernatant is a highly purified concentrated suspension of SARS-CoV-2 with a biological titer of $n \times 10^{9} \mathrm{CPE}_{50} / \mathrm{ml}$.

A comparison of the yields of SARS-CoV-2/human/RUS/Nsk-FRCFTM-1/2020 in Vero and SPEV

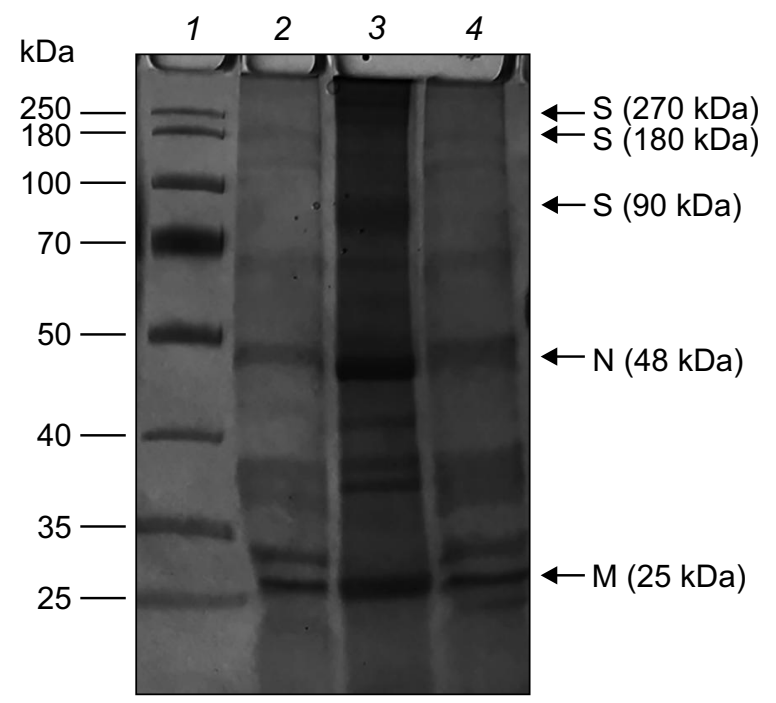

Fig. 1. Electrophoretic pattern of the proteins of purified concentrated SARS-CoV-2/human/RUS/Nsk-FRCFTM-1/2020 and SARS-CoV strain Frankfurt 2002 in Vero and SPEV cell cultures. 1) Molecular weight markers; 2, 4) purified SARS-CoV-2 produced in Vero and SPEV cultures, respectively; 3) purified SARS-CoV strain Frankfurt 2002 produced in Vero.

cell cultures of the same volumes demonstrated that the yield of the purified virus preparation was higher in SPEV cells $(1$ and $1.5 \mathrm{mg} / \mathrm{ml}$, respectively; the concentration was determined on a spectrophotometer using a Protein Assay Kit; Bio-Rad).

Protein electrophoresis (Fig. 1) demonstrated that the produced virus preparations contained membrane protein $\mathrm{M}$ and nucleoprotein $\mathrm{N}$ with molecular weight of 25 and $48 \mathrm{kDa}$, respectively. Outer glycoprotein $\mathrm{S}$ (spike) is presented by three modifications: trimer $(>270 \mathrm{kDa})$, dimer $(180 \mathrm{kDa})$, and monomer $(90 \mathrm{kDa})$, which agrees with published data [9].

The profiles of structural proteins of SARSCoV-2/human/RUS/Nsk-FRCFTM-1/2020 and SARS$\mathrm{CoV}$ strain Frankfurt 2002, which has been stored since 2003 as a purified virus lysate at $-80^{\circ} \mathrm{C}$ coincide with a minor visualized difference in the molecular weight of the nucleoprotein (Fig. 1). The N protein of SARS-CoV strain Frankfurt 2002 emerged to be more electrophoretically mobile, presumably, because of different hydrophobicity/hydrophilicity of its constituent amino acid residues.

Structural proteins $\mathrm{S}, \mathrm{N}$, and $\mathrm{M}$ of coronaviruses are highly immunogenic (Qiu, 2005; Guan, 2004) and represent a good substrate for serological studies of the sera of the recovered and vaccinated individuals [15]. In our purified inactivated SARS-CoV-2/human/ RUS/Nsk-FRCFTM-1/2020 preparation, these proteins interact well with the blood serum antibodies of COVID-19 convalescents. Interestingly, an immunoblot of the purified SARS-CoV-2 strain Frankfurt 2002 preparation with the blood serum sample of the same 
COVID-19 convalescent also shows the interaction with all proteins.

Our results demonstrate that the SARS-CoV-2 virus preparations obtained using the described method are good for studying the blood sera of both convalescents and vaccinated individuals in order to assess the intensity of the immune response in ELISA and to detect the target proteins in immunoblotting.

Thus, the method used for SARS-CoV-2 concentration and purification is efficient, gives a considerable increase in the yield of the purified whole-virion SARS-CoV-2 material, and is convenient for production of the initial preparation for pathophysiological, immunological, hemostatic, and other studies of the native virus proteins both within the virion and separately.

The work was supported by the Russian Foundation for Basic Research (grant No. 20-04-60010; Viruses: The Research into Diversity, Circulation, and Pathogenic Potential of Coronaviruses in Natural Reservoirs of Western and Eastern Siberia).

\section{REFERENCES}

1. Ustinova EN, Shestopalov AM, Bakulina LF, Chepurnov AA. Titration of Ebola and Marburg viruses by plaque formation under semi liquid agar cover. Vopr. Virusol. 2003;48(1):43-44. Rusian.

2. Chepurnov AA, Dadaeva AA, Malkova EM, Sandakhchiev LS, Kolesnikov RSI. Symptoms of infection caused by SARS coronavirus in laboratory mice and guinea pigs. Dokl. Biol. Sci. 2004;397(1-6):310-313. doi: 10.1023/B:DOBS. 0000039701.92375.b6

3. Chepurnov AA, Merzlikin NV, Ryabchikova EI, Chepurnova TS, Volchkov VE, Istomina NN, Kuzmin VA, Vorobeva MS. Isolation of purified Ebola virus. Vopr. Virusol. 1994;39(6):254257. Russian.

4. Chepurnov AA, Sharshov KA, Kazachinskaya EI, Kononova YuV, Kazachkova EA, Khripko OP, Yurchenko KS, Alekseev AYu, Voevoda MI, Shestopalov AM. Antigenic properties of SARS-CoV-2/HUMAN/RUS/NSK-FRCFTM-1/2020 coronavirus isolate from a patient in Novosibirsk. Zh. Infectol. 2020;12(3):42-50. doi: 10.22625/2072-6732-2020-12-3-42-50

5. Bielinska AU, Chepurnov AA, Landers JJ, Janczak KW,
Chepurnova TS, Luker GD, Baker JR. A novel, killedvirus nasal vaccinia virus vaccine. Clin. Vaccine Immunol. 2008;15(2):348-358. doi: 10.1128/CVI.00440-07

6. Chepurnov AA, Bakulina LF, Dadaeva AA, Ustinova EN, Chepurnova TS, Baker JR Jr. Inactivation of Ebola virus with a surfactant nanoemulsion. Acta Trop. 2003;87(3):315-320. doi: 10.1016/s0001-706x(03)00120-7

7. Chepurnov AA, Tuzova MN, Ternovoy VA, Chernukhin IV. Suppressive effect of Ebola virus on $\mathrm{T}$ cell proliferation in vitro is provided by a $125-\mathrm{kDa}$ GP viral protein. Immunol. Lett. 1999;68(2-3):257-261. doi: 10.1016/s0165-2478(99)00058-9

8. Dent S, Neuman BW. Purification of coronavirus virions for Cryo-EM and proteomic analysis. Methods Mol. Biol. 2015;1282:99-108. doi: 10.1007/978-1-4939-2438-7_10

9. Gao Q, Bao L, Mao H, Wang L, Xu K, Yang M, Li Y, Zhu L, Wang N, Lv Z, Gao H, Ge X, Kan B, Hu Y, Liu J, Cai F, Jiang D, Yin Y, Qin C, Li J, Gong X, Lou X, Shi W, Wu D, Zhang H, Zhu L, Deng W, Li Y, Lu J, Li C, Wang X, Yin W, Zhang Y, Qin C. Development of an inactivated vaccine candidate for SARS-CoV-2. Science. 2020;369:77-81. doi: 10.1126/ science.abc1932

10. Hamouda T, Chepurnov A, Mank N, Knowlton J, Chepurnova T, Myc A, Sutcliffe J, Baker JR. Efficacy, immunogenicity and stability of a novel intranasal nanoemulsion-adjuvanted influenza vaccine in a murine model. Hum. Vaccin. 2010;6(7):585-594. doi: 10.4161/hv.6.7.11818

11. Neuman BW, Adair BD, Yeager M, Buchmeier MJ. Purification and electron cryomicroscopy of coronavirus particles. Methods Mol. Biol. 2008;454:129-136. doi: 10.1007/978-159745-181-9_12

12. Salk J, Salk D. Control of influenza and poliomyelitis with killed virus vaccines. Science. 1977;195:834-847. doi: 10.1126/science.320661

13. Wang H, Zhang Y, Huang B, Deng W, Quan Y, Wang W, Xu W, Zhao Y, Li N, Zhang J, Liang H, Bao L, Xu Y, Ding L, Zhou W, Gao H, Liu J, Niu P, Zhao L, Zhen W, Fu H, Yu S, Zhang Z, Xu G, Li C, Lou Z, Xu M, Qin C, Wu G, Gao GF, Tan W, Yang X. Development of an Inactivated Vaccine Candidate, BBIBP-CorV, with Potent Protection against SARS-CoV-2. Cell. 2020;182(3):713-721.e9. doi: 10.1016/j.cell.2020.06.008

14. WHO Coronavirus (COVID-19) Dashboard. World Health Organization. [URL: https://covid19.who.int/].

15. Yan Y, Diao B, Liu Y, Zhang W, Wang G, Chen X. Severe Acute Respiratory Syndrome Coronavirus 2 Nucleocapsid Protein in the Ocular Tissues of a Patient Previously Infected With Coronavirus Disease 2019. JAMA Ophthalmol. 2020;138(11):12011204. doi: 10.1001/jamaophthalmol.2020.3962 